\title{
Model of Factors Impact on the CRM Performance
}

\author{
Pham Thi Thanh HONG ${ }^{1 *}$ and Hoang Van DONG ${ }^{2}$ \\ ${ }^{1}$ School of Economics and Management, Hanoi University of Science and Technology \\ ${ }^{2}$ School of Economics and Management, Hanoi University of Science and Technology, \\ *Corresponding author: hong.phamthithanh@hust.edu.vn
}

\begin{abstract}
Customer Relationship Management (CRM) plays a crucial role toward a company. These days, CRM is considered the strategic approach to the most profitable customers. However, to master such powerful tool to develop strong customer relationships, and in turn, to maximize the potential benefits, the company should recognize and control all factors influencing CRM performance to effectively apply this business process management strategy to improve the customer service.
\end{abstract}

\section{Research purpose:}

This study aims to explore the key factors that impact on CRM performance. Besides, the study is going to analyze how each key factor affects CRM performance and which internal and external factors may alter the performance results in companies. The results should come up with a theoretical framework to analyze factors altering the CRM performance.

\section{Research motivation:}

CRM helps companies to understand customer requirements thoroughly; solving problems for the customers with CRM ecosystem; always value customer's valuable time and provide solutions accordingly the customer potentials. However, not all companies have an effective CRM system due to the variation in firm's culture, resources, and procedures. Therefore, it is necessary to identify the factors that affect CRM performance.

\section{Research design, approach and method:}

The paper is an integrated literature review. The authors collected the papers from Web-based articles, search engines such as ScienceDirect, Springer, Google Scholar, ResearchGate, and Scientific journals to review, criticize, and figure key factors influencing CRM performance. Based on the extensive review of the factors and essential elements that contribute to success of CRM project implementation, this paper attempts to identify and explain key factors that impact on the CRM performance in a company.

\section{Main findings:}

The paper proposes a model with 5 key factors, including: (1) Organizational performance, (2) Customer, (3) Process, (4) Technology and (5) Other resources. This model helps companies build a framework for customer relationship management of the current customer base with measurable targets, recognizing the full value potential of existing customer relationships.

\section{Practical/managerial implications:}

This study synthesizes and analyzes the results of previous studies, from which proposing a model of factors impact on CRM performance. The study strengthens the understanding of the implications of effective customer value management in the changing environment. This is also the basis for performing other studies such as evaluating the CRM performance of a particular industry.

Keywords: Customer Relationship Management, CRM, CRM performance 


\section{INTRODUCTION}

The expression, Customer Relationship Management (CRM), has been in use since the early 1990s (S.Makan, 2019). It has grown from a tactical marketing tool to a strategic element in all marketing decisions. The growth of the Internet also has increased the adoption rate of CRM in many industries. Today, CRM refers to a strategy, a set of tactics, and a technology that has become essential in the modern economy (W.Reinartz, 2012).

The application of CRM is said to bring great value. According to Keith A. Richards and Eli Jones, there are seven core benefits: improved ability to target profitable customers, integrated offerings across channels, improved sales force efficiency and effectiveness, individualized marketing messages, customized products and services, improved customer service efficiency and effectiveness and improved pricing (Jones, 2008). CRM has evolved into a major task within companies due to changes in technology and the resultant power of consumers (Mohammed T. Nuseir, 2020).

However, successful application of CRM is not simple. According to IDC (International Data Corporation) and Gartner Group, the rate of successful CRM implementations is below $30 \%$ (Vasna, 2017). Although the success rate of CRM has certainly been improved, it is still not high because CRM is very complex. Recently, modern firms faced gradual but still seismic changes with respect to four major forces: consumers, marketplaces, technology, and marketing functions (W.Reinartz, 2012).

Currently, there are many research dealing with CRM implementation, but less mentioned the key factors that impact CRM performance. Most of research focused on CRM successes or failures, but less recommended to have an organizational evaluative mechanism to manage, control, and assess the performance of CRM implementation and operational practices (Kim, 2009; Mohammed; 2020; Reinartz, 2012; Makan, 2019; Vasna, 2017; Jones, 2008).

Then, this article aims to synthesize the previous research results, and identify the key factors that impact on CRM performance. Analyze how each key factor impacts on CRM performance.

In addition, this article also aims to build the basis for other studies on CRM and CRM performance. Future research may lead to quantitative research in a clearer and more specific audience.

\section{METHODOLOGY}

Methodologically, this article is an integrated literature review because it reviewed, criticized, and synthesized representative literature on key factors impact on CRM performance. At the end of the article, the research integrated significant findings in literature and developed a new framework on the topic that can be tested empirically in future research. The article is therefore underpinned by an extensive literature review to establish key factors impact on CRM performance.

The sources that were consulted included:

- Web-based articles.

- Search engines such as ScienceDirect, Springer, Google Scholar, ResearchGate.

- Scientific journals included: Expert Systems with Applications, Business Process Management Journal, Industrial Marketing Management, Journal of Business Management and Accounting, and the like

- Textbooks and eBooks.

For the research results related to key factors impact on CRM performance, this article uses the results of 15 previous articles from 2009 to 2019 published in international scientific journals.

\section{THEORETICAL BACKGROUND}

\subsection{What is customer relationship management (CRM)?}

There have been many attempts to define the domain of CRM. As a discipline hotly contested by various information technology (IT) vendors, consultants and academics, a clear consensus has not yet emerged (S.Makan, 2019). Many definitions of CRM are suggested by researchers, some examples are: Gamble, Stone and Woodcock (Gamble, 1999); Jain (Jain, 2005); Evans, O’Malley and Patterson (Evans, 2004);...

There is a lot of debate about the concept of CRM, however many scholars agree that there are three types of CRM. According to Makan (2019), there are three CRM types, including: Strategic CRM, Operational CRM and Analytical CRM.

Strategic CRM is a core customer-centric business strategy that aims at winning and keeping profitable customers. Strategic CRM is focused upon the development of a customer centric business culture 
dedicated to winning and keeping customers by creating and delivering value better than competitors.

Operational CRM focuses on the automation of customer-facing processes such as selling, marketing and customer service. CRM software applications enable the marketing, selling and service functions to be automated and integrated.

Analytical CRM, also called analytic CRM, is the process through which organizations transform customerrelated data into actionable insight for either strategic or tactical purposes.

\subsection{CRM performance}

CRM performance is the output of CRM implementation in the firm. The results can be demonstrated through many criteria and have specific measures. The end result, however, must still be the impact on profits.

To understand CRM performance, it is necessary to understand an effective CRM system or a successful CRM system. A successful CRM system empowers a firm to perform ten actions that will lead to strategic advantages (W.Reinartz, 2012).

- Integrate and consolidate customer information

- Provide consolidated information across all channels

- Manage customer cases

- Personalize

- Automatically and manually generate new sales opportunities

- Generate and manage campaigns

- Yield faster and more accurate follow-up

- Manage all business processes

- Give top managers a detailed and accurate picture

- Instantly react to changing market environments

Based on the theory, CRM performance can be defined as how many actions the system helps firm to perform. The unification of theoretical framework helps to establish the basis for research activities in this study.
CRM represents a strategy for creating value for both the firm and its customers through the appropriate use of technology, data and customer knowledge. This strategy requires focus, training, and investment in new technology and software to aid in the development of value-adding CRM systems (Tim Coltman, 2011). Many researchers have tried to point out the factor impact on CRM performance. Sometimes, this is similarly understood as the factors impact on CRM application.

Many studies have analyzed and built models of key factors impact on CRM performance, typical examples are: The IDIC model (Peppers, 1996); 5-process model of CRM (Payne, 2013); SCHEMA model; CRM scorecard model (Kim, 2009); (Hamideh Soltani, 2013).

\section{DISCUSSION}

\subsection{Factors impact on CRM performance}

Each researcher has its own theoretical framework with different factors (Table 1). However, all these factors can be divided into 8 key factors including: Leadership and strategy; Organizational performance; Process; Technology; Data; Customer; Human and Other organizational resources.

\section{Leadership and strategy}

Leadership and strategy are the knowledge and capabilities of a leader as well as having a good strategy in business. This factor can guide the operation of the CRM system in the firm.

Leadership and strategy have become an important key in all aspects of the CRM process, which helps in getting successful CRM. Thus, managers must manage and update their knowledge to identify and achieve the customers' needs as fast as they can (Elham, 2016; Hamideh, 2013; Mahdi, 2012).

Table 1: Summary of previous research results

\begin{tabular}{|c|l|l|}
\hline Research & \multicolumn{1}{|c|}{ Source } & \multicolumn{1}{c|}{ Factors } \\
\hline (Peppers, 1996) & -London: Piatkus & - Identify \\
& & - Differentiate \\
& & - Interact \\
& & \\
& & - $u$ stomize \\
\hline (Popovich, 2003) & - Business Process & - People \\
& Management Journal & - Process \\
& & - Technology \\
\hline
\end{tabular}




\begin{tabular}{|c|c|c|}
\hline Research & Source & Factors \\
\hline $\begin{array}{l}\text { (Kim, 2009) } \\
\text { (Mohammad Ali } \\
\text { Shafia, 2011) }\end{array}$ & $\begin{array}{l}\text { - Industrial Marketing } \\
\text { Management } \\
\text { - Industrial Management \& } \\
\text { Data Systems }\end{array}$ & $\begin{array}{l}\text { - Organizational performance } \\
\text { - Customer perspective } \\
\text { - Process perspective } \\
\text { - Infrastructure }\end{array}$ \\
\hline $\begin{array}{l}\text { (Tim Coltman, } \\
\text { 2011) }\end{array}$ & $\begin{array}{l}\text { - Journal of Information } \\
\text { Technology }\end{array}$ & $\begin{array}{l}\text { - Human Knowledge } \\
\text { - IT Infrastructure } \\
\text { - Business Architecture }\end{array}$ \\
\hline $\begin{array}{l}\text { (Bas ar Öztaysi, } \\
\text { 2011) } \\
\text { (Elham Ebrahimi, } \\
\text { 2016) }\end{array}$ & $\begin{array}{l}\text { - Expert Systems with } \\
\text { Applications } \\
\text { - Iranian Journal of } \\
\text { Management Studies }\end{array}$ & $\begin{array}{l}\text { - Customer } \\
\text { - CRM process } \\
\text { - CRM output } \\
\text { - Infrastructure } \\
\text { - Organizational alignment }\end{array}$ \\
\hline $\begin{array}{l}\text { (Sarmad Alshawi, } \\
\text { 2011) }\end{array}$ & $\begin{array}{l}\text { - Industrial Marketing } \\
\text { Management }\end{array}$ & $\begin{array}{l}\text { - Organisational factors } \\
\text { - Technical factors } \\
\text { - Data quality factors }\end{array}$ \\
\hline (Payne, 2013) & - Cambridge University Press & $\begin{array}{l}\text { - The strategy development process } \\
\text { - The value creation process } \\
\text { - The multi-channel integration process } \\
\text { - The performance assessment process } \\
\text { - The information management process }\end{array}$ \\
\hline $\begin{array}{l}\text { (Hamideh Soltani, } \\
\text { 2013) }\end{array}$ & $\begin{array}{l}\text { - Research Journal of Applied } \\
\text { Sciences, Engineering and } \\
\text { Technology }\end{array}$ & $\begin{array}{l}\text { - Technology factor } \\
\text { - Human factor } \\
\text { - Processes factor }\end{array}$ \\
\hline $\begin{array}{l}\text { (Vesna Tornjanski, } \\
\text { 2017) }\end{array}$ & $\begin{array}{l}\text { - Management: Journal of } \\
\text { Sustainable Business and } \\
\text { Management Solutions in } \\
\text { Emerging Economies }\end{array}$ & $\begin{array}{l}\text { - Financial perspective } \\
\text { - Customer Perspective } \\
\text { - Innovation and Learning Perspective } \\
\text { - Internal Business Process Perspective }\end{array}$ \\
\hline $\begin{array}{l}\text { The SCHEMA } \\
\text { model (2018) }\end{array}$ & $\begin{array}{l}\text { - The Customer Framework } \\
\text { (TCF) }\end{array}$ & $\begin{array}{l}\text { - Direction and leadership } \\
\text { - IT } \\
\text { - Data management capabilities } \\
\text { - Organizational culture and competencies of people }\end{array}$ \\
\hline (Saxena, 2018) & $\begin{array}{l}\text { - Int. J. Public Sector } \\
\text { Performance Management }\end{array}$ & $\begin{array}{l}\text { - Customer experience } \\
\text { - Technology orientation } \\
\text { - Organisational commitment } \\
\text { - Process-driven approach and reliability }\end{array}$ \\
\hline $\begin{array}{l}\text { (Muhamad Fairos } \\
\text { Mohamad Shah, } \\
\text { 2019) }\end{array}$ & $\begin{array}{l}\text { - Journal of Business } \\
\text { Management and Accounting }\end{array}$ & $\begin{array}{l}\text { - Financial Strategy } \\
\text { - Location Strategy } \\
\text { - Technology Strategy }\end{array}$ \\
\hline $\begin{array}{l}\text { (Qusay H. Al- } \\
\text { Salami, 2019) }\end{array}$ & $\begin{array}{l}\text { - Journal of Humanities and } \\
\text { Social Sciences }\end{array}$ & $\begin{array}{l}\text { - Technology } \\
\text { - Human Resource } \\
\text { - Knowledge of CRM } \\
\text { - Knowledge Management }\end{array}$ \\
\hline
\end{tabular}




\section{Organizational performance}

The measures for organizational performance should be able to indicate whether a corporate CRM strategy contributes to bottom-line improvement. Therefore, it is preferable to measure the direct economic effect of CRM initiatives, the company's profitability, and the overall value of the company (Kim, 2009).

According to Mohammed (2020), organizational performance can be assessed by customer equity, profitability, and shareholder value.

\section{Process}

Since any corporate business strategy should be implemented by a group of activities leading to desired business outcomes, measuring corporate performance in the process perspective is regarded as imperative (Kim, 2009). In this paper, we define the CRM process as a series of activities for acquiring, retaining, and expanding the relationship with customers. With a CRM process, companies can contact customers prudently and manage the relationship differently in each distinct relationship phase, and such corporate relationship practices lead to augmenting buyers' trust and ultimately to cooperative relationships.

According to Bas et la (2011), process is customer targeting, enquiry management, customer knowledge generation, campaign management, managing problems and product logistics.

\section{Technology}

Technology is a tool, but it also makes changes in customer relationship management. Thanks to the advancement of technology, especially information technology, companies can easily reach customers even with operations that were previously unavailable.

The technology role enables CRM use (Prasanna, 2014) and allows organizations to achieve better customization and greater service at a lower cost (Mahdi, 2012).

Moreover, technologies play significant roles in companies' CRM programs and chiefly for those with huge customer bases. In fact, CRM technology is the backbone of various operational aspects of CRM, such as the automation of the sales force and operations of the call center (Qusay H. Al-Salami, 2019). Accordingly, it is necessary from both perspectives of administrative and academic departments to understand how organizations use, implement, and take advantage of these technologies (Saxena, 2018).
In this study, the technology in question has the same meaning as information technology because it is the main industry that exerts an impact on customer relationship management.

\section{Data}

The company cannot focus on customers without knowing the customers' needs (Qusay H. Al-Salami, 2019). Customer needs drive CRM strategies to clarify customer needs through customer information analysis. Having data is very important, it determines whether the CRM system is working in the right direction or not.

\section{Customer}

Kim (2009) affirmed that there are three factors in the customer key factor that should be considered, including: Customer acquisition, customer retention and customer loyalty. The customer is at the center of the CRM system, so the customer-related issues have an impact on CRM performance.

Customer acquisition indicates success of the company in acquiring profitable new customers. Besides the shift to retention of customers, getting new customers are still very important in the marketing activities. Targeting profitable customers, integration offerings across channels and improved pricing are most important drivers of CRM activities (Richards, 2008), (Bas ar Öztaysi, 2011).

Customer retention criteria represents the achievement of the company in keeping the existing customers. CRM aims to improve economic performance of companies by affecting customer retention, customer acquisition and development of customers with up sell and cross sell activities (Kim, 2009).

Customer loyalty is a term that defines the customers' behavioral and attitudinal bond with the company. While altitudinal loyalty is determined with surveys and other qualitative studies, behavioral loyalty can be analyzed using companies' salary records. In the customers dimension scope, customer loyalty is close to attitudinal loyalty. On the other hand, behavioral loyalty is parallel to customer retention criteria in CRM outputs dimension. Customer loyalty is a consequence of customer satisfaction and can be improved by CRM (Bas ar Öztaysi, 2011).

\section{Human}

Human resources are a part of the CRM system. Although currently the role of human has been reduced 
because of technology and processes, it is still an indispensable factor.

As for human resource and its relationship with CRM, Prasanna (2014) has mentioned that human resources positively affect CRM implementation. "It has been observed that the employees are the central effectiveness of CRM; so, due to the importance of the employees, organizations should manage its relationships with them if the organization seeks to serve well the customers. Thus, the company must consider the employees as the eyes of the customer.

\section{Other organizational resources}

In fact, all the relevant factors in firm impact CRM performance. However, not all factors have a clear impact. These factors can be grouped together as other organizational resources. They are infrastructure, partnership, organization culture, and organization structure (Qusay and Al-Salami, 2019).

\subsection{Key factors impact on CRM performance}

As mentioned, all factors in firm impact on CRM performance. However, only a few of the factors have a strong impact, which can be called as key factors.

Based on Resource Based View (RBV) theory, this study identifies key factors impact on CRM performance. The main factor is one that has the following properties (Barney, 1991):

Value
In $\mathrm{RBV}$, a resource has value when it enables an organization to implement strategies to improve efficiency and effectiveness.

\section{Rarity}

Rarity refers to the condition where the resource is not simultaneously available to many firms.

\section{Inimitability}

Inimitability is an attribute of a resource that makes it almost impossible for other firms to duplicate it. Resources would become very difficult to duplicate when they are deeply integrated into a firm through its unique developmental path, such as brand loyalty and company culture. Such resources are also characterized by social complexity.

\section{Non-substitutability}

Non-substitutability is an attribute of a resource which makes it difficult to replace with another resource that yields equivalent benefits. When an organization is in possession of a rare and inimitable resource, competitors may seek to match up by acquiring a substitute resource. In ensuring that the resource is also non substitutable, the organization is in a competitively superior position that is not easily matched by competitors.

All factors are valuable to the firm, but not all factors can satisfy other properties. There are factors that businesses can easily obtain at a low cost. There are a few other factors that are easily copied or replaced by other factors. After the analysis, the authors gave the results (Table 2)

Table 2. Analysis of factors according to RBV

\begin{tabular}{|c|c|c|c|c|}
\hline & Value & Rarity & Inimitability & $\begin{array}{c}\text { Non- } \\
\text { substitutability }\end{array}$ \\
\hline Leadership and strategy & $\mathrm{x}$ & & & $\mathrm{x}$ \\
\hline Organizational performance & $\mathrm{x}$ & $\mathrm{x}$ & $\mathrm{x}$ & $\mathrm{x}$ \\
\hline Process & $\mathrm{X}$ & & & $\mathrm{X}$ \\
\hline Technology & $\mathrm{x}$ & $\mathrm{x}$ & $\mathrm{x}$ & $\mathrm{x}$ \\
\hline Data & $\mathrm{x}$ & & & $\mathrm{x}$ \\
\hline Customer & $\mathrm{x}$ & $\mathrm{x}$ & $\mathrm{x}$ & $\mathrm{x}$ \\
\hline Human & $\mathrm{x}$ & $\mathrm{x}$ & $\mathrm{x}$ & \\
\hline Other organizational resources & $\mathrm{X}$ & & & \\
\hline
\end{tabular}


Table 3. Factors in the studies over time

\begin{tabular}{|c|c|c|c|c|c|c|c|c|c|c|c|c|}
\hline & $<2009$ & 2009 & 2010 & 2011 & 2012 & 2013 & 2014 & 2015 & 2016 & 2017 & 2018 & 2019 \\
\hline $\begin{array}{l}\text { Leadership and } \\
\text { strategy }\end{array}$ & & & & & & $*$ & & & & & $*$ & $* *$ \\
\hline $\begin{array}{l}\text { Organizational } \\
\text { performance }\end{array}$ & & $*$ & & $*$ & & $*$ & & & & $*$ & & $*$ \\
\hline Process & $*$ & $*$ & & $*$ & & $* *$ & & & $*$ & $*$ & $*$ & \\
\hline Technology & $*$ & & & $* *$ & & $* *$ & & & & & $* *$ & $* *$ \\
\hline Data & & & & $*$ & & $*$ & & & $*$ & & $*$ & \\
\hline Customer & & $*$ & & $*$ & & & & & $*$ & $*$ & $*$ & \\
\hline Human & $*$ & & & $*$ & & $*$ & & & & & & $*$ \\
\hline $\begin{array}{l}\text { Other organizational } \\
\text { resources }\end{array}$ & & $*$ & & $* * *$ & & & & & $*$ & $*$ & $* *$ & $*$ \\
\hline
\end{tabular}

Each $*$ is the time that the factor has been mentioned in studies

In addition, the key factor determination can also be based on the results of other researchers. Arranging the above key factors by the time mentioned in previous research. Each time the key factor is mentioned corresponds to one $(*)$, the results are presented in Table 3.

Obviously, the process factor is mentioned by most researchers, which shows the great impact of the process on CRM performance. In addition, the technology factor in recent times has been mentioned a lot, showing the increasing role of technology in the CRM system.

\section{RESULTS}

Based on these results, the author proposes a model with 5 key factors, including:

- Organizational performance

- Customer

- Process

- Technology

- Other resources

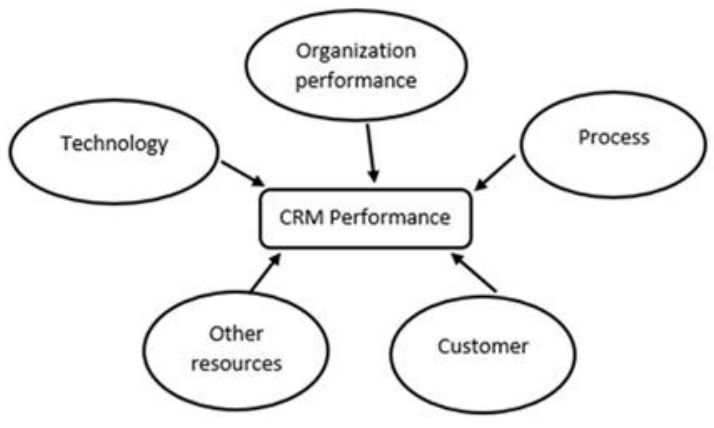

Figure 1: Model of factors impact on CRM performance (Authors)

Firstly, rapid innovative technology impacts enterprises in every manner including customer relationship management. Technology has enhanced the opportunities to capture higher-quality customer data, increased focus on customer relationship, rise of customer insight and CRM practices (Elham, 2016; Hamideh, 2013; Qusay and Al-Salami, 2019). Currently, conventional methods of collecting information, storing, analyzing and interacting with customers have been integrating with technology. Many solutions and systems are applied to reduce unnecessary human involvement, avoid a series of errors, and increase work productivity. Some specific applications can be mentioned as digitizing systems, 
storing non-physical data, automated systems for analysis, reporting, interaction, and customer feedback. The application of technology also changes customer relationship management process, information resource as well as impact directly to CRM performance.

Secondly, successful CRM performance has also been linked to an organization's ability to identify and respond to potential barriers within organizational culture; the culture of sharing of information across departments; as well as the overall performance of the organization. An organizational environment that promotes an atmosphere of risk that can create confidence for employees to act in the best interests of customers. This kind of environment encourages employees to be more innovative in their efforts to overcome any problems in the CRM implementation and can generate a better CRM outcome (Gamble, 1999; Elham, 2016; Makan, 2019; Saxena, 2018; Mohammad, 2020).

Thirdly, business processes, structures, and competencies are essential for developing strategies for improving organizational performance (Prasanna, 2014; Muhamed, 2019; Payne, 2013). Therefore, essential requirements for CRM effective performance are customer interaction management, sharing customer information and data, and the overall business process (Muhamed, 2019; Payne, 2013; Popovich, 2003; Hamideh, 2013).

Fourthly, customers themselves make great impact on CRM performance of each company. Legacy or innovative customers must have different reactions to the company's marketing campaigns, promotions, as well as customer relationship policies. Innovative customers are very advanced, tech savvy and with high expectations in terms of any product they buy. Different from legacy customers, innovative customers' needs and wants are dynamic in nature. Therefore, companies will have tough time understanding these users as their priorities change all the time (Elham, 2016; Hamideh, 2013; Qusay and Al-Salami, 2019; Muhamed, 2019; Payne, 2013; Elham, 2016; Makan, 2019; Saxena, 2018).

Finally, digital transformation, which is directly the process of using technology and developing new capabilities, brings many new products and services to the market. Previously, products and services were mainly provided directly between organizations and customers, but now can be done through information technology tools. New types of products and services lead firms to search for new resources, new processes, new technologies, and of course, require firms to catch up and ensure safe and appropriate service provision, especially in CRM.

\section{CONCLUSIONS}

To contribute to existing literature on customer value management, the study merely focuses on factors impacting CRM performance. The result of the study affirms 5 key factors: (1) Organizational performance, (2) Customer, (3) Process, (4) Technology, and (5) Other resources.

The study increases understanding of the implications of effective customer value management in the changing environment. In terms of managerial goals, it helps companies build a framework for customer relationship management of the current customer base with measurable targets, recognizing the full value potential of existing customer relationships. This is also the basis for performing other studies such as evaluating the CRM performance of a particular industry.

In addition, this is also the basis for further theoretical development in the future. These studies can focus on how factors influence CRM performance or ranking factors' impact. These studies may also be done by industry or geography to verify the theory.

\section{REFERENCES}

[1] Barney, J. (1991). Firm Resources and Sustained Competitive Advantage. Journal of Management. 17 (1), 99-120.

[2] Bas ar Öztaysi, T. K. (2011). Performance comparison based on customer relationship management using analytic network process. Expert Systems with Applications 38, 9788-9798.

[3] Elham Ebrahimi, M. R. (2016). A new hybrid method based on fuzzy Shannon's Entropy and fuzzy COPRAS for CRM performance evaluation (Case: Mellat Bank). Iranian Journal of Management Studies (IJMS) Vol. 9, No. 2, 333-358.

[4] Evans, O. a. (2004). Exploring direct and customer relationship marketing. London: Thomson.

[5] Gamble, S. a. (1999). Customer relationship marketing: up close and. London: Kogan Page.

[6] Gartner Inc. . (2012). www.crmsearch.com/crmmarket.php.

[7] Hamideh Soltani, S. K. (2013). Design a Model to Assess CRM Maturity in the Organization Using AHP. 
Research Journal of Applied Sciences, Engineering and Technology 5(15), 3851-3864.

[8] Jain. (2005). CRM shifts the paradigm. Journal of Strategic Marketing, 13 (December).

[9] Jones, K. A. (2008). Customer relationship management: Finding value drivers. Industrial Marketing Management 37, 120-130.

[10] Khushboo, B. (2015). Trends in HRM and CRM. IJRAR International Journal of Research and Analytical Reviews, 2(1), 49-53.

[11] Kim, H.-S. K.-G. (2009). A CRM performance measurement framework: Its development process and application. Industrial Marketing Management 38, 477489.

[12] Mahdi, B. M. (2012). Information Technology (IT) as an Improvement Tool for Customer Relationship Management (CRM). The First International Conference on Leadership, Technology, and Innovation Management, 59-64.

[13] Mohammad Ali Shafia, M. M. (2011). Applying fuzzy balanced scorecard for evaluating the CRM performance. Industrial Management \& Data Systems Vol. 111 No. 7, 1105-1135.

[14] Mohammed T. Nuseir, A. A. (2020). Factors affecting the use of social networks as a customer relationship management tool. International Journal of Business Information Systems.

[15] Muhamad Fairos Mohamad Shah, S. W. (2019). The relationship between Technology, Financial and location strategies and CRMP among logistics service Providers. Journal of Business Management and Accounting, Vol. 9 (1), 15-25.

[16] Payne, A. a. (2013). Strategic customer management: integrating CRM and relationship. Cambridge University Press, 211.

[17] Peppers, D. a. (1996). The 1-to-1 future: building business relationships one customer at a time. London: Piatkus.
[18] Popovich, C. \&. (2003). Understanding Customer Relationship Management (CRM). Business Process Management Journal, 5, 672-688.

[19] Prasanna, M. K. (2014). Information technology: Roles, advantages and disadvantages. International Journal of Advanced Research in Computer Science and Software Engineering, 10(4), 203-312.

[20] Qusay H. Al-Salami, I. A. (2019). The Factors Affecting Customer Relationship Management Implementation at DHL Company in Baghdad, Iraq. Journal of Humanities and Social Sciences Volume III, No. 1, 43-51.

[21] Richards, K. A. (2008). Customer relationship management: Finding value drivers. Industrial Marketing Management, 37(2), 120-130.

[22] Rigby, D. R. (2002). Avoid the Four Perils of CRM. Harvard Business Review, 80(2), 101-109.

[23] S.Makan, F. \&. (2019). Customer Relationship Management: Concepts and Technologies-Fourth Edition. Routledge.

[24] Sarmad Alshawi, F. M. (2011). Organisational, technical and data quality factors in CRM adoption SMEs perspective. Industrial Marketing Management 40, 376-383.

[25] Saxena, N. (2018). A study on CRM effectiveness in public and private sector banks. Int. J. Public Sector Performance Management, Vol. 4, No. 1, 45-56.

[26] Tim Coltman, T. M. (2011). Customer relationship management and firm performance. Journal of Information Technology 26, 205-219.

[27] Vesna Tornjanski, S. K. (2017). A CRM Performance Measurement in Banking Using Integrated BSC and Customized ANP-BOCR Approach. Management: Journal of Sustainable Business and Management Solutions in Emerging Economies 22(1), 71-85.

[28] W.Reinartz, V. \&. (2012). Customer Relationship Management Concept, Strategy, and Tools-Second Edition. Springer. 